\title{
Desempenho acústico em edificações residenciais - ainda em 2022, construtoras não se adequaram a aplicação da Norma ABNT-NBR 15575
}

\author{
Acoustic performance in residential buildings - still in 2022 construction companies have not \\ adequate the application of the ABNT-NBR 15575 standard \\ Desempeño acústico en edificios residenciales - aún en 2022 las constructoras no tienen adecuada la \\ aplicación de la norma ABNT-NBR 15575
}

Recebido: 20/01/2022 | Revisado: 24/01/2022 | Aceito: 27/01/2022 | Publicado: 28/01/2022

\author{
Lucas Marques Resende \\ ORCID: https://orcid.org/0000-0002-7331-345X \\ Universidade de Gurupi, Brasil \\ E-mail: lucasresende1855@gmail.com \\ Marcio Barbosa Martins de Oliveira \\ ORCID: https://orcid.org/0000-0003-1363-3803 \\ Universidade de Gurupi, Brasil \\ E-mail: marciomartinsbarbosaa@gmail.com \\ Fabiano Fagundes \\ ORCID: https://orcid.org/0000-0002-6008-5806 \\ Universidade de Gurupi, Brasil \\ E-mail: fabianofagundes@unirg.edu.br \\ Gabriel Alves Ferreira \\ ORCID: https://orcid.org/0000-0002-4359-2291 \\ Universidade de Gurupi, Brasil \\ E-mail: gabriel.engenharia00@gmail.com
}

\begin{abstract}
Resumo
O presente artigo tem como cerne apontar, de maneira objetiva, as principais dificuldades encontradas pelas construtoras para seguir os requisitos da NBR 15575, em relação ao desempenho acústico, que se tornou parâmetro para a execução de projetos executados a partir de 19 de julho de 2013. Concluiu-se que um dos obstáculos encontrados para se colocar em prática a referida norma, de forma eficaz, de maneira que atenda todas as cláusulas, acontece sobretudo, por não haver no mercado mão e obra suficientemente qualificada em todos os níveis da construção, a iniciar pela equipe técnica e até o staff de execução. Para tanto, foi feito uma revisão bibliográfica da literatura em trabalhos de conclusão de curso, artigos e revistas especializadas sobre construção civil. Autores como Santos e Hippert (2016), Cordovil (2013), Gil (2017), Litwinczik (2016), Britz (2018), Akkerman, Pierrard e Chrischon (2022), entre outros, foram citados ao longo do artigo, para fundamentar a pesquisa.

Palavras-chave: NBR 15575:2021; Desempenho Acústico; Custos de aplicação.
\end{abstract}

\begin{abstract}
This article aims to objectively point out the main difficulties encountered by construction companies to follow the requirements of NBR 15575, about acoustic performance, which has become a parameter for the execution of projects executed from July 19, 2013. The study concluded that one of the obstacles encountered in putting this standard into practice, efficiently and effectively, in a way that meets all the clauses, is, above all, due to not finding qualified labor and labor in the market, at all levels of construction, starting with the technical team and up to the executive staff. For that, a bibliographic review of the literature was carried out, searching in course conclusion works, articles, and specialized magazines on civil construction. Authors such as Santos and Hippert (2016), Cordovil (2013), Gil (2017), Litwinczik (2016), Britz (2018), Akkerman, Pierrard and Chrischon (2022), among others, were cited throughout the article to support the research.
\end{abstract}

Keywords: NBR 15575:2021; Acoustic Performance; Application costs.

\section{Resumen}

Este artículo tiene como objetivo señalar objetivamente las principales dificultades encontradas por las empresas constructoras para seguir los requisitos de la NBR 15575, en relación con el rendimiento acústico y el rendimiento acústico, que se ha convertido en un parámetro para la ejecución de proyectos ejecutados a partir del 19 de julio. 2013. El estudio concluyó que uno de los obstáculos encontrados para poner en práctica esta norma, de manera eficiente y eficaz, de manera que cumpla con todas las cláusulas, se debe, sobre todo, a no encontrar mano de obra calificada y 
mano de obra en el mercado, en todos los niveles de la construcción, desde el equipo técnico hasta el personal de ejecución. Para ello, se realizó una revisión bibliográfica de la literatura, buscando en trabajos de conclusión de curso, artículos y revistas especializadas en construcción civil. Autores como Santos y Hippert (2016), Cordovil (2013), Gil (2017), Litwinczik (2016), Britz (2018), Akkerman, Pierrard y Chrischon (2022), entre otros, fueron citados a lo largo del artículo para apoyar la investigación.

Palabras clave: NBR 15575:2021; Rendimiento Acústico; Costos de aplicación.

\section{Introdução}

A norma da ABNT NBR 15575 (2013) sobre Edificações Habitações - Desempenho, cognominada de Norma de Desempenho, recém atualizada, entrou em vigor a partir da data de 19 de julho de 2013. Obras, cujos projetos foram aprovados antes desta data, não tinham como parâmetros os quesitos determinados por essa norma. Tomando como base a acústica nas construções, a proteção sonora, que é uma das premissas apresentadas pela NBR 15575:2021, quando não atendida gera incômodo aos moradores. Portanto, percebe-se que as empreiteiras no geral, mesmo os projetos que não seguem essa normativa, começaram a se adequar, pelo menos aos pressupostos básicos, a fim de permanecerem ativas no mercado de trabalho. No entanto, as construtoras, ao procurarem seguir a NBR 15575:2021, têm se deparado com um grande problema que é a falta de mão de obra qualificada.

$\mathrm{Na}$ atualidade, as construtoras não contam com nenhum órgão fiscalizador que avalie se o procedimento construtivo está de acordo com a norma citada. Quando há a necessidade, geralmente por litígio, essa função fica a cargo dos clientes. E no que tange ao conforto acústico, a Norma de Desempenho refere-se, principalmente aos ruídos mínimos toleráveis. Isso não significa que entre as unidades do edifício não haverá barulho, mas o máximo ruído aceitável para a comodidade auditiva, visto que tal atributo relaciona-se diretamente com a saúde do morador da edificação.

Para que os métodos de construção relacionados a acústica predial sejam eficazes, é preciso fazer experimentos, e esses acontecem de duas formas: Método de Engenharia e Método Simplificado de Campo. Akkerman et al. (2022), afirmam que, para se analisar os ruídos aéreos, poderá ser feito uma simulação das interferências sonoras no ambiente por meio de um instrumento omnidirecional, por isso, o método de Engenharia é o que dará um resultado mais preciso. Para analisar o impacto desses ruídos, os testes são feitos por meio de um equipamento de impacto, situado no ambiente superior (apartamento acima, que emite o som), e dentro do apartamento inferior (que recebe os ruídos). Esse mesmo tipo de experiência se faz nas vedações internas e externas, mas sempre avaliando as esquadrias. Por isso, é imprescindível avaliar, dentro do projeto, as especificações detalhadas desses subsídios, para que o sistema seja válido, quando submetido aos experimentos.

Esse artigo se justifica por apontar as principais dificuldades que as construtoras têm para se adequarem a NBR 15575:2021, em relação ao desempenho acústico, bem como sinalizar saídas capazes de avalizar o procedimento executivo na gestão da eficácia, no que se refere ao cumprimento da norma supracitada.

Segundo Mourão, et al. (2016), a NBR 15575 constitui-se por mencionar, de forma técnica, os pré-requisitos que servirão como padrão para assegurar a qualidade da construção, além disso, é um guia que norteará futuros problemas com fiscalizações.

Baseado na justificativa dessa pesquisa, as indagações básicas, que deverão ser respondidas ao longo do trabalho, serão: Quais são as principais dificuldades encontradas para a aplicação da NBR 15575:2021 (Desempenho acústico)? Como assegurar a eficácia dos métodos construtivos que seguem a norma supracitada?

O objetivo geral desse artigo é apontar as principais dificuldades encontradas pelas construtoras para atingir os requisitos da NBR 15575:2021 em relação ao desempenho acústico. 


\section{Metodologia da Pesquisa}

O método de pesquisa utilizado nesse estudo é de natureza aplicada, intentando produzir entendimento prático em relação a norma NBR 15575, cláusula relacionada ao desempenho acústico, mostrando princípios para a implantação, bem como as dificuldades encontradas. A pesquisa aplicada tem como meta produzir conhecimento para poder aplicar, na prática, a solução de problemas inerentes a alguma área do conhecimento (Moreti, 2021).

De acordo com os objetivos, esse estudo pode ser rotulado como exploratório, descritivo ou explicativo e o estudo descritivo intui-a apresentar eventos sobre determinada realidade (Gil, 2017; Marconi \& Lakatos, 2021). A pesquisa praticada nesse neste artigo é classificada como descritiva, pois tensiona averiguar um problema específico, em ralação a aplicabilidade da NBR 15575:2021, com a intenção de torná-lo mais compreensível e exequível, mostrando fases, com o levantamento bibliográfico.

Em relação à aplicabilidade, este artigo apresenta uma abordagem qualitativa. Conforme cita Presado, Baixinho e Oliveira (2021) "investigação qualitativa permite a compreensão de realidades singulares que, dificilmente, são apreendidas a partir de um único prisma, assumindo-se cada vez mais como um campo inter e transdisciplinar".

\section{Resultados e Discussões}

\subsection{Caracterização da Norma de Desempenho NBR 15575:2021}

Para Alves (2021), a norma de desempenho é tida como referência para as autoridades judiciárias no Brasil. Assim sendo, o não cumprimento da norma é considerado um ato irregular. Além do mais, seguir os padrões exigidos na norma caracterizam-se como um dever ético dos responsáveis por uma habitação.

Segundo Cordovil (2013), a norma de desempenho surgiu em 2008. No entanto, as construtoras não viram com "bons olhos" essas mudanças, pois alegaram que o país não estava preparado pata atender tantos recursos, principalmente, no que tange a esfera tecnológica. Diante dessas alegações, pesquisadores e profissionais gabaritados da ABNT estenderam o prazo de sua indispensabilidade, passando a ser obrigatório o seu cumprimento a partir do ano de 2013, para que as construtoras pudessem se adequar. Então, a partir de 19 de julho de 2013, passou a ser primordial atender a NBR 15575.

\footnotetext{
"A norma estabelece requisitos a serem cumpridos pelos envolvidos no processode construção, desde sua etapa de concepção projetual até o fim da vida útil da edificação. Estes requisitos se referem aos sistemas construtivos constituintes da edificação" (Santos \& Hippert, 2016, p. 04).
}

Entende-se que para os autores supracitados, a norma NBR 15575 tem como propósito fundamental produzir um memorando útil para a os stakeholders, pois ao especificar as ferramentas utilizadas durante o processo, ao mesmo tempo que auxilia na eficácia da construção, serve como direcionamento no âmbito judicial, tanto para o contratante como para o contratado. A norma é válida para todos que participam do processo: projetistas, usuários, fornecedores de materiais, construtoras e clientes. Apresenta-se ramificada, tendo suas partes:
1) Requisitos Gerais;
2) Sistemas Estruturais;
3) Sistemas de Pisos;
4) Sistemas de Vedações Verticais Internas e Externa (SVVIE);
5) Sistemas de Cobertura;
6) Sistemas Hidrossanitários; 
Santos e Hippert (2016), são contundentes ao afirmarem que, para se cumprir as exigências da NBR 15575 em relação ao desempenho acústico, é necessário atender as partes 1, 3, 4 e 5.

Os Requisitos Gerais da ABNT NBR 15575-1 (2021), constituem uma série de premissas para atender a norma. Nesta parte, nos itens, são relatadas as funções e obrigações de todos que fazem parte do processo, através de memorandos, petições e registros de garantias.

Com respeito ao Sistemas de Vedações Verticais Internas e Externas da ABNT NBR 15575-4 (2021), entende-se que o sistema tem que operar em harmonia coma estrutura, pois recebem as ações resultantes da sua circulação. Por isso, é preciso que o diagnóstico do sistema de vedação seja feito em conjunto com as informações, itens e normas que se completam, como molduras, esquadrias, pisos e instalações. Quando essas especificações são atendidas, os barulhos nas habitações tendem a diminuir.

No que tange o Sistema de cobertura ABNT NBR 15575-5 (2021), as funções pela performance acústica do sistema são divididas em categorias, contanto que este abranja o atendimento mínimo da norma.

\subsection{Exemplo de projeto acústico}

$\mathrm{Na}$ fase de projeto é necessário definir o grau de assistência e seguimento das normas. Para isso, existem três pontos panoramas distintos: mínimo, intermediário e superior. Estabelecido qual dos cenários irá seguir, é preciso reconhecer e diferenciar as restrições e ressalvas exteriores que a obra deparará, como barulhos de automóveis nas vias públicas, fábricas localizadas próximo ao empreendimento, ruídos de aviões, entre outros, para que, a partir daí, possam tomar atitudes para diminuir essas condicionantes.

Para Litwinczik (2016), o tipo de vedação externa, para atender minimamente a norma, depende do local que o estabelecimento está inserido, e dos decibéis $(\mathrm{dB})$ externos, por exemplo: Uma edificação instalada longe de fortes ruídos de qualquer natureza é considerada com desempenho acústico, quando os decibéis medidos internamente forem menores ou iguais a $20 \mathrm{~dB}$. Habitações localizadas em locais que serão expostas a algum tipo de ruído, poderão atingir um nível de até $25 \mathrm{~dB}$; e habitações sujeitas a grandes ruídos, por motivos diversos, chegam a ser superior a $30 \mathrm{~dB}$. De posse dessas informações, o engenheiro ou autor do projeto, determina a espessura das paredes de vedação, tanto dos ambientes internos quanto externos. Ainda de acordo com o autor, em cômodos em que o ruído chega a $40 \mathrm{~dB}$, a espessura da parede tem que ser aproximadamente de $19,0 \mathrm{~cm}$, com $3,0 \mathrm{~cm}$ de revestimento.

\subsection{Método para assegurar a eficácia do projeto acústico}

Quando decidir por implantar um projeto acústico em uma construção, precisa-se tomar algumas precauções durante sua execução, a fim de assegurar a eficiência planejada. Litwinczik (2016), descreve, em seu laudo, que paredes em que dividem duas casas iguais espelhadas na planta, necessitam conservar um espaço de 6,0 cm entre os tijolos, a fim de criar um bolsão de ar, com o objetivo de bloquear o alastramento dos ruídos. Esse afastamento dificultará para que o som se propague.

Britz (2018), cita que: “... ainda em relação as paredes geminadas, deve-se acrescentar uma chapa de gesso, acrescida de lã de vidro, ou preencher um bloco de alvenaria com argamassa ou vermiculita". Tudo isso é necessário para diminuir o impacto dos ruídos em prédios conjugados.

Litwinczik (2016), esclarece em seus documentos o modelo de laje e as espessuras de piso que devem ser empregadas para abafar os ruídos, além da utilização do contrapiso flutuante, onde o contrapiso fica "flutuando" sobre a camada do material isolante acústico. Especialistas e fornecedores desse tipo de cobertura, que atenua os sons, recomendam que ela deve ser sobreposta em ambientes limpos e sem saliências que possam esburacá-la. Além disso, deve ser colocado uma manta acústica no rodapé, envolvendo todas as partes das paredes até o lado da cantaria, virada para o interior do prédio. Os 
construtores têm que prestarem atenção nas emendas das mantas, em relação à penetrabilidade mínima recomendada pelo fabricante, com a propósito de não advir áreas sem cobertura, que poderão afetar o isolamento ideal em relação a propagação do som.

De acordo com o descrito acima, podemos exemplificar a figura 1, que demonstra o desempenho acústico de paredes e lajes quanto a sua espessura.

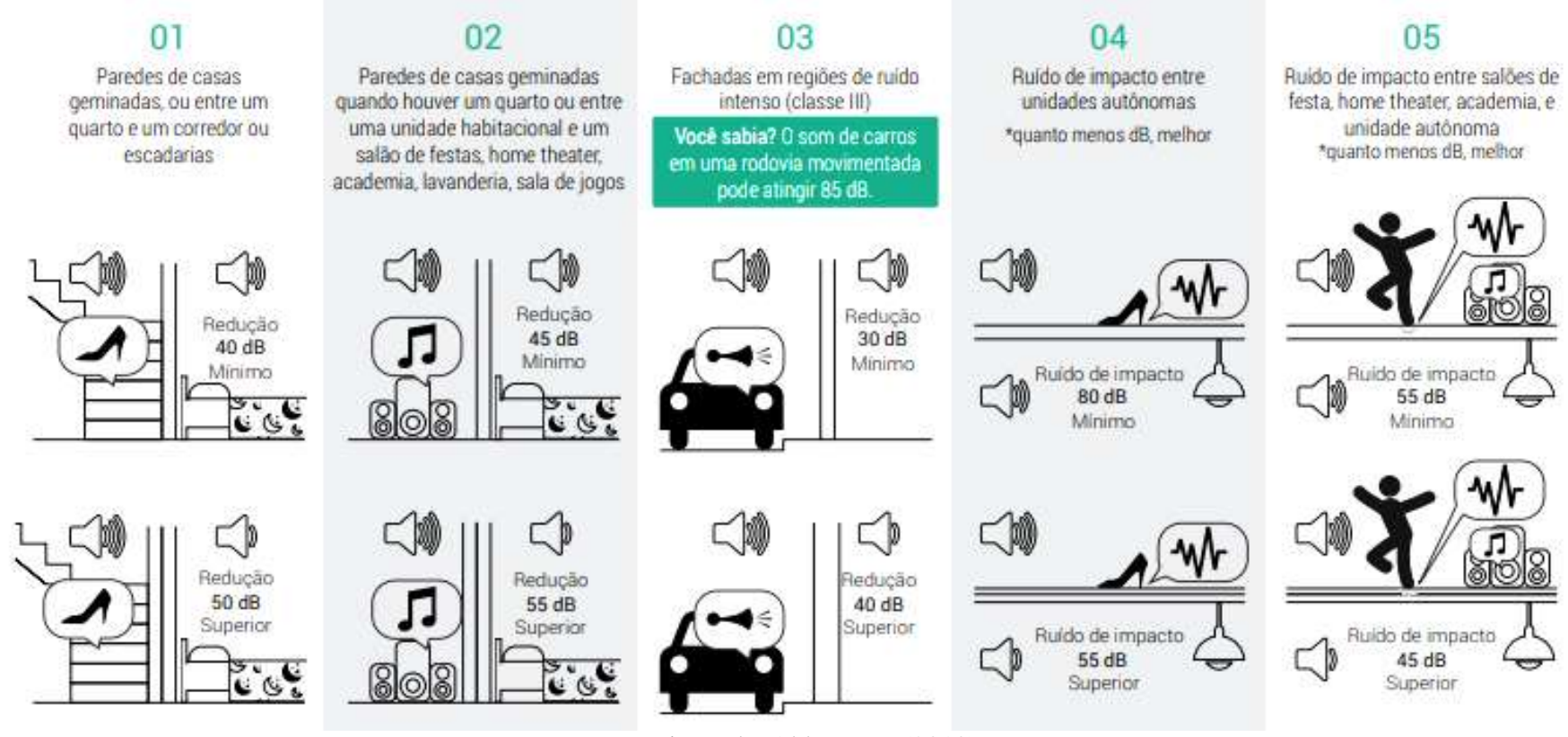

Fonte: Pierrard e Akkerman, (2013).

Na parte 01 e 02 de (paredes internas que separam dois cômodos) e parte 03 (paredes internas que separam os cômodos de áreas comuns), quanto mais espessa a parede, maior é a redução do ruído entre as áreas. Nas partes 04 e 05 da figura 01, está demonstrado o ruído de impacto no sistema de piso, onde o ruído de impacto passante é maior em sistemas menos espessos e menor quando é aplicado camada atenuante.

Quando os elementos utilizados para o fechamento dos vãos forem de madeira, Litwinczik (2016), sugere que essas sejam maciças, com medida mínima de 4,0 cm de espessura, e que no momento de instalar, preencha todo o espaço oco com espuma de poliuretano entre a madeira, e que deixe um espaço entre a soleira e a parte inferir da porta de $3 \mathrm{~mm}$ de distância, no máximo.

No que se refere ao sistema hidráulico, Litwinczik (2016), recomenda que as tubulações devem ser envelopadas com lã de vidro e que durante esse processo, alguns cuidados devem se tomados para evitar que o revestimento se comprima muito, formando uma camada de ar, que pode prejudicar o funcionamento do sistema. Para as canalizações que ficam na parte superior das construções, pode ser usado o Selênio, que é um objeto mais resistente, pois devido suas paredes internas serem maiores, isso ajuda a diminuir os ruídos. Há também uma advertência sobre o local onde os ralos são fixados, pois quando estes são colocadas sob os jatos do chuveiro, há uma tendência de aumentar o barulho.

Quanto ao sistema hidrossanitário, Diógenes (2017) frisa que ele é avaliado por aparelhos que funcionam ininterruptamente durante um período de trinta segundos, apontando o coeficiente da quantidade de ruído dentro dos quartos.

A Tabela 1 demonstra a alguns padrões para assegurar a eficácia do isolamento acústicos entre unidades. 
Tabela 1. Diferença padronizada de nível ponderada da vedação externa, dB.

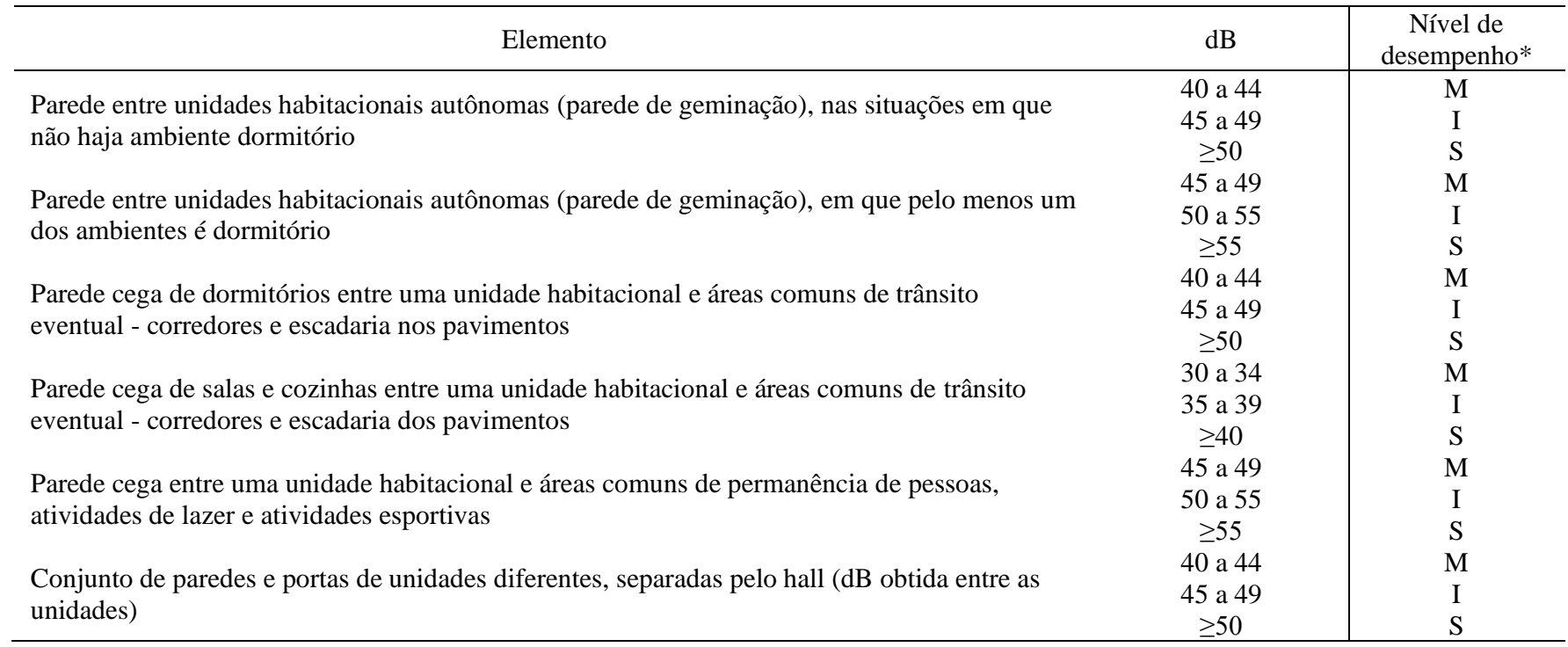

*M: mínimo; I: Intermediário: S: superior. Fonte: Adaptado da NBR 15575-4 (2021).

\subsection{Dificuldades encontradas pelas construtoras para implantarem a NBR 15575:2021}

Para que o sistema de Desempenho Acústico seja eficaz, é fundamental que a equipe técnica, envolvida no processo seja experiente. Britz (2018), corrobora ao afirmar que a grande dificuldade que as construtoras se deparam para a implantação da NBR 15575, é a falta de conhecimento teórico suficiente sobre a norma e, automaticamente, os profissionais envolvidos não demostram destreza durante a atuação técnica. Uma grande parcela das empresas de construção no Brasil não possui um departamento técnico específico para tratar de normas e métodos de aplicação das regras. Talvez, devido a própria formação (onde se trabalha muito cálculo e prática, e menos teoria), os profissionais têm dificuldade em buscar informações em fontes confiáveis como revistas especializadas, artigos ou mesmo fazer cursos para melhorar o conhecimento. Portanto, genericamente, esses seriam os principais obstáculos para executar a Norma de Desempenho na construção civil.

Outro fator que reforça a falta de interesse em buscar informações e conhecimento sobre a norma, é a falta de um órgão fiscalizador. Em razão disso, os autores Kern, Silva e Kazmierczak (2014), afirmam que as construtoras acabam empregando procedimentos administrativos e métodos técnicos que não atendem completamente a NBR 15575, tornando-se ineficaz, pois quando tencionarem a atender apenas as condições mínimas necessárias, as falhas administrativas e técnicas são inevitáveis, o que comprometem a eficácia dos resultados.

Entre os fatores apresentados, também, onde os empreendedores procuram otimizar os custos, a fim de se tornarem competitivos, em um ramo onde há muita concorrência. Esse interesse em diminuir valores em relação a matéria prima e mão de obra, por vezes, compromete a qualidade do serviço prestado e da obra em si, quando relacionadas às condições básicas para atender a Norma de Desempenho.

\subsection{Avaliação do custo para implantar a norma de desempenho}

Para que as construtoras possam atender a Norma de Desempenho, elas terão que ponderar, em seu projeto orçamentário, um emprego de capital. Esses valores se referem às estratégias administrativas, suporte de especialistas gabaritados, e detalhamento do projeto de acordo com cada fase que será executada. Quando há uma análise detalhada desses processos, entende-se que o custo do projeto tende a aumentar.

Para Cordovil (2013), o valor previsto para executar um projeto de desempenho acústico é difícil de ser especificado, por causa da inexistência de relatos de experiências e de resultados que construtoras obtiveram. Mas, considera-se que o 
investimento gira entre $0,5 \%$ e $2 \%$ do valor total da obra. Entende-se que, nesse artigo, esse valor é estimado apenas para a fase que se refere ao isolamento acústico.

Assim sendo, as empreiteiras consideram que a execução do projeto que atenda as demandas de desempenho, são tidas como custo extra. No entanto, se essa parcela de empresários ponderasse sobre a seriedade e responsabilidade da questão, onde a NBR 15575 menciona sobre a importância da conservação da obra, aumentando a vida útil da mesma, esse montante passaria a ser considerado como investimento. Cordovil (2013), justifica que a implementação da Normas de Desempenho, a certo nível, barateia a construção, e não o contrário.

\section{Considerações Finais}

Ainda que a NBR 15575 tenha entrado em vigor em junho de 2013, muitas construtoras ainda não possuem conhecimento sobre o valor que deverá ser investido para atender aos requisitos mínimos exigidos em relação ao desempenho acústico. Calcula-se que se deve empregar um capital entre $0,5 \%$ e 2,0\% do valor total da construção. A dificuldade em estipular um valor exato, relacionada a complexidade de afiançar que o sistema implantado acate as condições mínimas da norma, dificulta, para os empresários, em venderem esse tipo empreendimento, pois ele não tem condições de garantir a eficácia do serviço que será oferecido.

À vista disto, é imprescindível um projeto executivo contendo, em pormenores, todas as fases do processo construtivo. Isso terá que ocorrer através da coordenação de profissionais experientes, pois, somente dessa maneira, a equipe poderá chegar a um resultado satisfatório em relação a implementação da NBR 15575:2021 de desempenho acústico.

Quando se trabalha com a norma de desempenho, todos os envolvidos no processo são responsáveis: construtora, engenheiros, projetistas, construtores, pedreiros, serventes, fornecedores e contratantes. Por isso, as construtoras têm que ter ciência que, com a norma em vigência, é necessário fazer um levantamento de profissionais capacitados no mercado, que que possam assegurar a eficiência da obra. Isso significa investimento, e não custos adicionais. Quando os stakeholders entenderem essa dinâmica, essa matemática começará a fazer sentido, pois resultará em serviços prestados de maior qualidade, com menos desperdício de material e eficiência nos resultados pretendidos.

É imprescindível que seja mostrado a exequibilidade e a importância da execução da Norma, para que, num futuro próximo, tenha mais subsídios para afirmar, com exatidão, quais são as maiores dificuldades que as construtoras encontram para se adequarem a NBR 15575:2021.

\section{Referências}

ABNT NBR 15575-1. de 30 de março de 2021. Edificações Habitacionais - Desempenho - Parte 1: Requisitos gerais. Associação Brasileira de Normas Técnicas.

ABNT NBR 15575-4. de 30 de março de 2021. Edificações Habitacionais - Desempenho - Parte 4: Requisitos para os Sistemas de Vedações Verticais internas e externas. Associação Brasileira de Normas Técnicas.

ABNT NBR 15575-5, de 30 de março de 2021. Edificações Habitacionais - Desempenho - Parte 5: Requisitos para os Sistemas de Coberturas. Associação Brasileira de Normas Técnicas.

ABNT NBR 15575, de 19 de julho de 2013. Desempenho de edificações. Associação Brasileira de Normas Técnicas.

Akkerman, D., Pierrard, J. F., \& Chrischon, D. (2022) Manual ProAcústica sobre a Norma de Desempenho ABNT NBR 15575:2021 - Acústica. (4a ed). Associação Brasileira para a Qualidade Acústica.

Alves, E. F. (2021). Engenharia Diagnóstica: ferramentas, conceitos e normas. Inteligência Urbana.

Britz, A. (2018). Desempenho na prática. In: Grupo de Pesquisa e Desenvolvimento.

Cordovil, L. A. B. L. (2013). Estudo da ABNT NBR 15575 - "Edificações habitacionais - Desempenho" e possíveis impactos no setor da construção civil na cidadedo Rio de Janeiro. Projeto de Graduação (Departamento de Construção Civil) - Escola Politécnica Universidade Federal do Rio de Janeiro, UFRJ. 
Research, Society and Development, v. 11, n. 2, e38711225984, 2022

(CC BY 4.0) | ISSN 2525-3409 | DOI: http://dx.doi.org/10.33448/rsd-v11i2.25984

Diógenes, H. (2017). Motivos que fazem o Projeto Hidráulico ser fundamental. Ime Junior. https://imejunior.com.br/2017/01/11/4-motivos-que-fazem-oprojeto-hidraulico/

Gil, A. C. (2017). Como elaborar projetos de pesquisa (6a ed). Atlas.

Gil, A. C. (2019) Método e técnicas de pesquisa social (7a ed). Atlas.

Kern, A. P., Silva, A., \& Kazmierczak, C. S. (2014). O processo de implantação de normas de desempenho na construção: um comparativo entre a Espanha (CTE) e Brasil (NBR 15575/2013). Gestão \& Tecnologia De Projetos, 9(1), 89-102. https://doi.org/10.11606/gtp.v9i1.89989

Litwinczik, V. (2016). Estudo Preliminar de Acústica - 08715.01 Residencial Black \& Blanc Florianópolis - SC. Anima Acústica tecnologia e conhecimento. https://animacustica.com.br

Marconi, M. A, \& Lakatos, E. M. (2021). Técnica de pesquisa. (9a ed). Atlas.

Moreti, I. (2021). Pesquisa aplicada: o que é, como fazer e exemplos. Via Carreira. https://viacarreira.com/pesquisa-aplicada/

Mourão, A. et al. (2016). Análise dos Critérios de Atendimento à Norma de Desempenho ABNT NBR 15.575: Estudo de Caso em Empresas do Programa Inovacon-CE.Ceará. Gadioli Cipolla Branding e Comunicação.

Pierrard, J. F., \& Akkerman, D. (2013). Manual ProAcústica sobre a Norma de Desempenho: Guia prático sobre cada uma das partes relacionadas à área de acústica nas edificações da Norma ABNT NBR 15575:2013 Edificações habitacionais - Desempenho ProAcústica. Associação Brasileira para a Qualidade Acústica.

Presado, M. H., Baixinho, C. L., \& Oliveira, E. S. F. (2021). Investigação qualitativa em tempos de pandemia. Revista Brasileira de Enfermagem. 74(1), e74Suppl101. https://doi.org/10.1590/0034-7167.202174Suppl101.

Santos, F., \& Hippert, M. A. (2016). O Impacto da Norma de Desempenho no Processo de Projeto. In. XII congresso nacional de excelência em gestão\& III INOVARSE http://www.inovarse.org/node/4589 